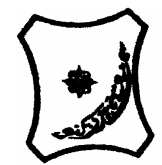

Bayero Journal of Pure and Applied Sciences, 3(2): 52 - 55

Received: June, 2010

Accepted: August, 2010

ISSN 2006 - 6996

\title{
STABILITY CONSTANT OF THE TRISGLYCINATO METAL COMPLEXES
}

\author{
J. Na'aliya and H.N. Aliyu
}

Department of Pure and Industrial Chemistry,Bayero University Kano, P. M. B. 3011, Kano,Nigeria

Correspondence: jnaaliya@yahoo.com

\section{ABSTRACT}

The stability constants of iron, manganese, cobalt, and nickel complexes of glycine have been determined in aqueous solution by potentiometric titration with standard sodium hydroxide solution. The values of the stepwise stability constants were obtained by ORIGIN '50' program. The overall stability constants of the complexes were found to be similar.

Keywords: Glycinato, titration, stepwise stability constants, origin '50' and toxicity

\section{INTRODUCTION}

Glycine belongs to amino acids that contain non polar $\mathrm{R}$ groups and it is the only aliphatic amino acid that does not show optical properties due to absence of chiral centre. Its function includes hormone production and cell making process (David and Micheal, 2000 and Stryer, 1988). Glycine acts as a bidentate ligand in its coordination with metal ions and stabilizes the complexes via hydrophobic interaction. The glycinato type of association serves as a basis of understanding the nature of metal amino acids interaction. The essential metals such as iron, manganese, cobalt and nickel play vital various roles in biological processes in form of complexes and their stability contributes to their efficiency. The roles played by these metals include catalysing enzymatic process, storage, checking of toxicity of metals at certain concentration (Stryer, 1988; David and Micheal, 2000 and Bala, 2005). Glycine forms tris complexes with metal ions in aqueous solution and therefore determination of stability constants will add to the few reported values that were reported for some of the complexes for comparison and better understanding of the working of metal ions and glycine. This paper reports the determination of stability constant of tris glycinato complexes of some essential transition metals.

$$
\begin{aligned}
& {\left[A^{-}\right]=\frac{K a}{H^{+}}\left(C_{H}-H^{+}\right)} \\
& n=\frac{A_{t o t}-\left(1+\frac{K a}{\left[H^{(+)}\right]}\right)\left(C_{H}-\left[O H^{-}\right]-\left[H^{+}\right]\right)}{M_{\text {tot }}}
\end{aligned}
$$

where $\mathrm{Ka}=$ dissociation constant of the amino acid

$\left[\mathrm{H}^{+}\right]=$concentration of the $\mathrm{H}^{+}$ion after each aliquot addition

$M_{\text {tot }} \mathrm{t}=$ total metal ion concentration.

$A_{\text {tot }}=$ total amino acid concentration.

$n=$ number of coordinated ligands.

$C_{H}=$ nitric acid concentration.

\section{MATERIALS AND METHODS}

All the chemicals used in this work are of AnalaR grade purity and were used without further purification. All weighing were carried out using electronic metler balance model $A B$ 54. The $\mathrm{pH}$ measurement was carried out using Jenway $\mathrm{pH}$ Meter model 3320.

Determination of stability constants of copper (II) amino acids complexes

Into a $400 \mathrm{~cm}^{3}$ beaker, $100 \mathrm{~cm}^{3}$ of $0.04 \mathrm{moldm}^{-3} \mathrm{KNO}_{3}$, $10 \mathrm{~cm}^{3}$ of $0.02 \mathrm{mo} \mathrm{Idm}^{-3} \mathrm{HNO}_{3}, 90 \mathrm{~cm}^{3}$ of distilled water and 1 millimole $(0.0001 \mathrm{~mol})$ of iron (II) ions were added respectively. Then $0.5 \mathrm{~cm}^{3}$ of $0.1 \mathrm{~mol} \mathrm{dm}^{-3}$ sodium glycinate was added and after each addition with stirring, the corresponding $\mathrm{pH}$ reading was recorded. The addition of the aliquots was continued until the full $10 \mathrm{~cm}^{3}$ was added. The same procedure was repeated with manganese (II), cobalt (II) and nickel (II) ions respectively.

The stepwise stability constants of the metal ion amino acids complexes were determined by new graphical/computational method, 'ORIGIN 50'. The graphs were obtained by plotting the values of $\log \left[\mathrm{A}^{-}\right]$ versus $n$ developed by Bjerrum (Angelici, 1977). The values of $\left[\mathrm{A}^{-}\right]$and $n$ were calculated from the experimentally known quantities using the expressions; 
The stepwise stability constants $\left(K_{1}, K_{2} a n d K_{3}\right)$, for each metal amino acid complex was determined from the plot of $\log \left[A^{-}\right]$versus number of coordinated ligands, using the relation;

$$
K_{n}=\frac{1}{\left[A^{-}\right]_{n}},
$$

where, $\mathrm{n}$ takes the values $1 / 2,1 / 2,2 \frac{1}{2}$. The overall stability constant for each complex was determined as product of the stepwise stability constants, $\log \beta=K_{1} \times K_{2} \times K_{3}$ (Angelici, 1977).

\section{RESULTS AND DISCUSSION}

The complex formation processes between metal ions and glycine results in the formation of $M L_{1} M L_{2}$ and $\mathrm{ML}_{3}$ parent complexes with metal ions favouring six coordination even though stability of these species slightly depends on the nature of non- coordinating side chains (Sovago et al., 1993). The glycine binds the metal ion through the amino and carboxylate groups. The coordination of this type is known as glycinate - like or glycinato like coordination. This mode of interaction lead to the formation of five membered chelating rings (Yamauchi and Odani, 1996).

The number of amino acid groups coordinated to each of the metal ions studied were found to be three and this is in agreement with the value reported for similar complexes such as $\left[\mathrm{Ni}(\mathrm{Ala})_{3}\right]^{-},\left[\mathrm{Co}(\mathrm{Ala})_{3}\right]^{-}$and $\left[\mathrm{Co}(\mathrm{Met})_{3}\right]^{-}$(Sovago et al., 1993 and Berthon, 1995). In both complexes, the values of the overall stability constants (Table 5) are high indicating good stability (Sovago et al., 1993 and Berthon, 1995). The stability of the complexes could be attributed to the number of chelate rings and their sizes (Cotton and Wilkinson, 1980; Satya, 2006). The values of the stepwise stability constants (Table 5) decreases in the order $\mathrm{K}_{1}>\mathrm{K}_{2}>\mathrm{K}_{3}$ and this is in agreement with pattern described by Angelici (1977), Cotton and Wilkinson (1980) and Satya (2006). The steady decrease in the values $K_{1}, K_{2}$ and $K_{3}$ with increase in the number of ligands is due to the fact that as more and more ligands move into the coordination zone, less and less aqua molecules are available to fresh ligands for replacement. Thus, the $\mathrm{Mn}$ (II) ion becomes less electrophilic with progressive intake of the ligands (amino acids) and this results in decrease in the values of the constants (Satya at al., 2006).

Similarly, the $\mathrm{pH}$ values (Tables $1-4$ ) increase with increase in the volume of NaGly. The values of the constants, $\log \beta$ (Table 5 ) were found to be similar due to the similarities in the ionic size of the metal ions as a result of the shielding effect of the $d-$ electrons across the third and fourth periods.

Table 1: Potentiometric titration results of manganese

\begin{tabular}{ll}
\hline NaGly & pH \\
\hline 0 & 3.30 \\
0.5 & 3.34 \\
1.0 & 3.40 \\
1.5 & 3.45 \\
2.0 & 3.53 \\
2.5 & 3.62 \\
3.0 & 3.75 \\
3.5 & 3.87 \\
4.0 & 4.08 \\
4.5 & 4.54 \\
5.0 & 5.98 \\
5.5 & 7.16 \\
6.0 & 7.88 \\
6.5 & 8.24 \\
7.0 & 8.40 \\
7.5 & 8.52 \\
8.0 & 8.63 \\
9.0 & 8.73 \\
9.5 & 8.81 \\
10 & 8.87 \\
\hline
\end{tabular}


Bajopas Volume 3 Number 2 December, 2010

Table 2: Potentiometric titration results of iron

\begin{tabular}{ll}
\hline NaGly & PH \\
\hline 0 & 3.40 \\
0.5 & 3.41 \\
1.0 & 3.50 \\
1.5 & 3.52 \\
2.0 & 3.57 \\
2.5 & 3.64 \\
3.0 & 3.71 \\
3.5 & 3.78 \\
4.0 & 3.87 \\
4.5 & 3.96 \\
5.0 & 4.11 \\
5.5 & 4.26 \\
6.0 & 4.46 \\
6.5 & 5.03 \\
7.0 & 5.51 \\
7.5 & 5.49 \\
8.5 & 5.82 \\
9.0 & 5.76 \\
9.5 & 5.33 \\
10 & 5.83 \\
\hline
\end{tabular}

Table 3: Potentiometric titration results of cobalt

\begin{tabular}{ll}
\hline NaGy & pH \\
\hline 0 & 3.30 \\
0.5 & 3.33 \\
1.0 & 3.40 \\
1.5 & 3.46 \\
2.0 & 3.54 \\
2.5 & 3.63 \\
3.0 & 3.73 \\
3.5 & 3.92 \\
4.0 & 4.11 \\
4.5 & 4.50 \\
5.0 & 5.72 \\
5.5 & 6.26 \\
6.0 & 6.50 \\
6.5 & 6.69 \\
7.0 & 6.82 \\
7.5 & 6.93 \\
8.0 & 7.06 \\
8.5 & 7.12 \\
9.0 & 7.17 \\
9.5 & 7.23 \\
10 & 7.29 \\
\hline
\end{tabular}

54 


\begin{tabular}{ll}
\hline NaGly & pH \\
\hline 0 & 3.30 \\
0.5 & 3.31 \\
1.0 & 3.40 \\
1.5 & 3.45 \\
2.0 & 3.51 \\
2.5 & 5.64 \\
3.0 & 3.72 \\
3.5 & 3.90 \\
4.0 & 4.13 \\
4.5 & 4.39 \\
5.0 & 4.97 \\
5.5 & 5.41 \\
6.0 & 5.60 \\
6.5 & 5.73 \\
7.0 & 5.84 \\
7.5 & 5.93 \\
8.0 & 6.02 \\
8.5 & 6.09 \\
9.0 & 6.16 \\
9.5 & 6.23 \\
10 & 6.27 \\
\hline
\end{tabular}

Table 5: Overall and stepwise stability constants of glycinato metal complexes

\begin{tabular}{lllll}
\hline Metal Complexes & $\mathbf{K}_{\mathbf{1}}$ & $\mathbf{K}_{\mathbf{2}}$ & $\mathbf{K}_{\mathbf{3}}$ & $\mathbf{L o g} \boldsymbol{\beta}$ \\
\hline$\left[\mathrm{Mn}(\mathrm{Gly})_{3}\right]^{-}$ & 9.14 & 9.12 & 8.99 & 27.25 \\
{$\left[\mathrm{Fe}(\mathrm{Gly})_{3}\right]^{-}$} & 9.17 & 9,17 & 9.09 & 27.43 \\
{$\left[\mathrm{Co}(\mathrm{Gly})_{3}\right]^{-}$} & 9.16 & 9.14 & 8.93 & 27.23 \\
{$\left[\mathrm{Ni}(\mathrm{Gly})_{3}\right]^{-}$} & 9.1 & 9.10 & 8.95 & 27.22 \\
\hline
\end{tabular}

\section{CONCLUSION}

The values of the overall stability constant of the triglycinato complexes of $\mathrm{Mn}(\mathrm{II}), \mathrm{Fe}(\mathrm{II}), \mathrm{Co}(\mathrm{II})$ and $\mathrm{Ni}(\mathrm{II})$ were found to be similar. The higher values

\section{REFERENCES}

Angelici, R. J. (1977). Synthesis and techniques in inorganic chemistry W. B. Saunders campany, $2^{\text {nd }}$ Edition Philadelphia, Pp 115 127.

Bala, M. (2005). Determination of some mineral Elements and Heavy metals in soils, water and lettuce collected from two pollution prone Irrigation Areas around Kano metropolis. Unpublished Usmanu Danfodio University, M.Sc., Dissertation, Sokoto.

Berthon, G. (1995). The Stability constants of metal complexes of Amino Acids with polar side chains. Pure and Appl. Chem.., 67 (7): 1117 -1240 .

Cotton, F. A. and Wilkinson, G. (1980). Advanced inorganic chemistry, A comprehensive Text, fourth Edition, John Wiley and Sons, New York, Pp $1310-1344$.

David L. and Micheal M. C. (2000). Lehninger Principles of Biochemistry, Third Edition, worth publishers, 41 Madison Avenue New York, Pp 113 - 158.

Satya, P; Tuli G. D.; Basu S. K. and Madan R. D. (2006). Advanced Inorganic Chemistry Vol. I S. chand and Company India Pp 705 - 706. account for the stability of the complexes and this further explain the ability of the metals to function effectively in biological systems.

Satya, P; Tuli G. D.; Basu S. K. and Madan R. D. (2006). Advanced Inorganic Chemistry Vol. II S. chand and Company India Pp $30-52$.

Sovago, I., Kiss, T. and Gergely, A. (1993) critical survey of the stability constants of complexes of Aliphatic Amino Acids. Pure and Appl. Chem.., 65 (5): 1029 - 1080.

Stryer, L. (1988). International student Edition Biochemistry, Third Edition W. H. Freeman and Company, NewYork Pp $15-42$. 